\title{
Thoracoscopy in the diagnosis of pleural effusion
}

\author{
A. CANTó, E. Blasco, M. CASillas, A. G. ZARZA. J. PADilla, J. PASTOR, \\ V. TARAZONA, AND F. PARÍS \\ From the Thoracic Surgery Service, Department of Surgery, Centro Hospitalario 'La Fé', \\ Valencia 9, Spain
}

Cantó, A., Blasco, E., Casillas, M., Zarza, A. G., Padilla, J., Pastor, J., Tarazona, V., and París, F. (1977). Thorax, 32, 550-554. Thoracoscopy in the diagnosis of pleural effusion. The technique, indications, and complications of diagnostic thoracoscopy are described. Two hundreof and eight explorations have been performed in our service in the last seven years. From 137 pleural malignancies we have obtained an unequivocal positive biopsy in $129(94 \%)$ with a minimum number of complications and no mortality. From our experience we conclude that thoracoscopy, when properly performed, is diagnostic in most pleural conditions.

An undiagnosed pleural effusion is often a difficult problem that needs histological study for a definitive aetiological diagnosis. In cases of malignant effusions of the pleura, blind biopsy using a needle (Abrams, 1968) has given a high percentage of negative results in our hands $(9 / 24=37 \cdot 5 \%)$ Three other specimens were of doubtful interpretation. For this reason we started to use diagnostic thoracoscopy in our service.

Thoracoscopy has not been widely used for diagnostic purposes. We collected information on the technique from the following authors: Matson (1936), Lloyd (1953), Delarue and Depierre (1956), Fleishman et al. (1956), Touraine (1960), Lagèze et al. (1960), Roche et al. (1963), Hatch and Decamp (1966), Sattler (1968), Brandt and Mai (1971), Decamp et al. (1973), Senno et al. (1974), and Lewis et al. (1976). We have been impressed by the ease and safety of the procedure.

\section{Material and methods}

From January 1970 to January 1977, 208 thoracoscopies were performed (Table 1); in 172 patients to try to determine the cause of a pleural effusion

Table 1 Indications for thoracoscopy

\begin{tabular}{lr}
\hline Pleural effusion & 172 \\
Pulmonary shadow $^{1}$ & 32 \\
Pleural foreign body & 2 \\
Pleurodesis for pneumothorax & 2 \\
\hline
\end{tabular}

${ }^{1}$ In most cases associated with pleural effusion. and in 32 to try to make the histological diagnosis of a pulmonary shadow with negative bronchoo scopy associated, in most cases, with a pleuras effusion. In another four patients we performe therapeutic thoracoscopies-to remove a foreigro body from the pleural cavity in two and to pere form pleurodesis for recurrent pneumothorax in $\vec{b}$ the other two.

At first we used a Kremer-Wolf-Zeiss G-1e thoracoscope. For the last five years we have used. a single trocar rigid fibreoptic Storz thoracoscope which has a Wolf 5.050 generator with an elec음 tronic flash incorporated for photography.

The position of the patient varies according tof the location of the pleural condition (Fig. 1). In total pleural effusion we have used an anterolatera thoracic approach through the seventh or eighth intercostal space. Generally we use local anaes음 thesia; when general anaesthesia was used, con $\Rightarrow$ trolled ventilation was achieved through a Carlens. endotracheal tube. After exploration an intra ON pleural drain is inserted and pleurodesis is per formed if malignancy is suspected.

\section{Results}

The malignant lesions have varied in appearanced from a solitary nodule to a widespread generalised carcinomatosis (Figs 2, 3, 4, and 5). Sometimes the pleura looks lumpy with whitish or reddish rugose areas isolated or confluent (as often occurs? in mesotheliomas).

When a pulmonary tumour is present we have 


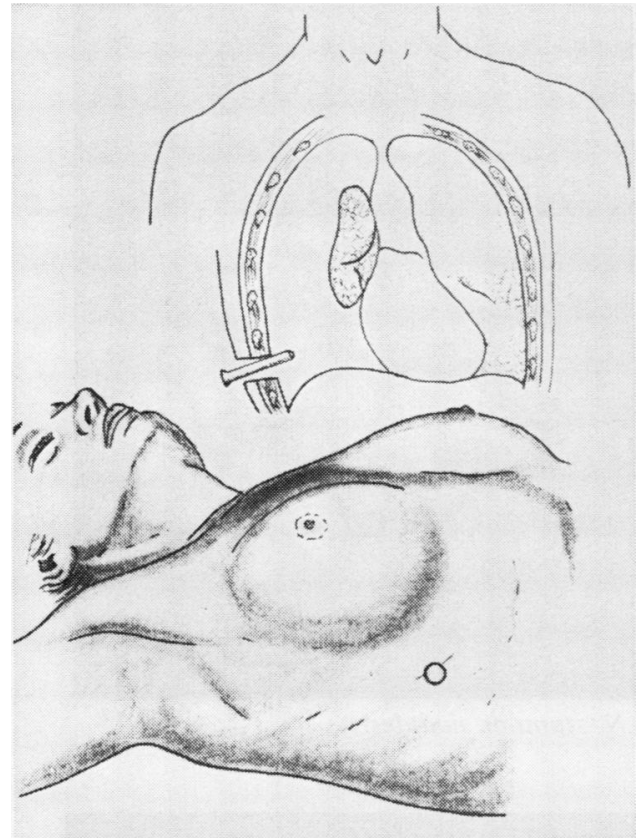

Fig. 1 Anterolateral thoracic approach commonly used.

sometimes been able to see the tumour on the lung surface, occasionally associated with white linear or star-shaped dilated lymphatic vessels.

In inflammatory conditions we have seen the following appearances: acute forms with a hyperaemic pleura sometimes showing areas of haemorrhage; subacute forms with white or yellow plaques and fibrin deposits; chronic forms showing an opalescent thickened shiny pleura, with little vascularity; tuberculous forms characterised by small, white-grey nodules spread over the pleural surface with or without detectable inflammatory change.

Other benign conditions were: pleural adhesions, cholesterol deposits and calcifications, osteophytes from ribs or vertebrae, thoracic lipomata and partial diaphragmatic eventrations, aneurysms of the great vessels, emphysematous bullae, and pulmonary cysts.

In Table 2 the histological diagnosis of the biopsies is shown, and in Table 3 the relation between the thoracoscopic appearance and the histological report is studied. In considering the result of explorations, we have related the visual aspect of the lesion and the histological report to the subsequent follow-up of the patient. From 137 pleural malignancies we have obtained 129 positive thoracoscopic biopsies (94\%). In eight cases, although the appearance and histology failed to

\section{Table 2 Histological diagnosis}

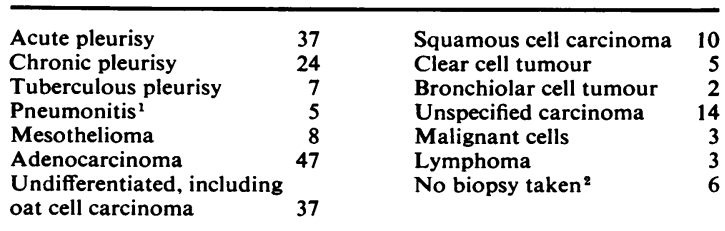

'Biopsy of normal visceral pleura and a piece of lung.

${ }^{2}$ Four were therapeutic thoracoscopies.
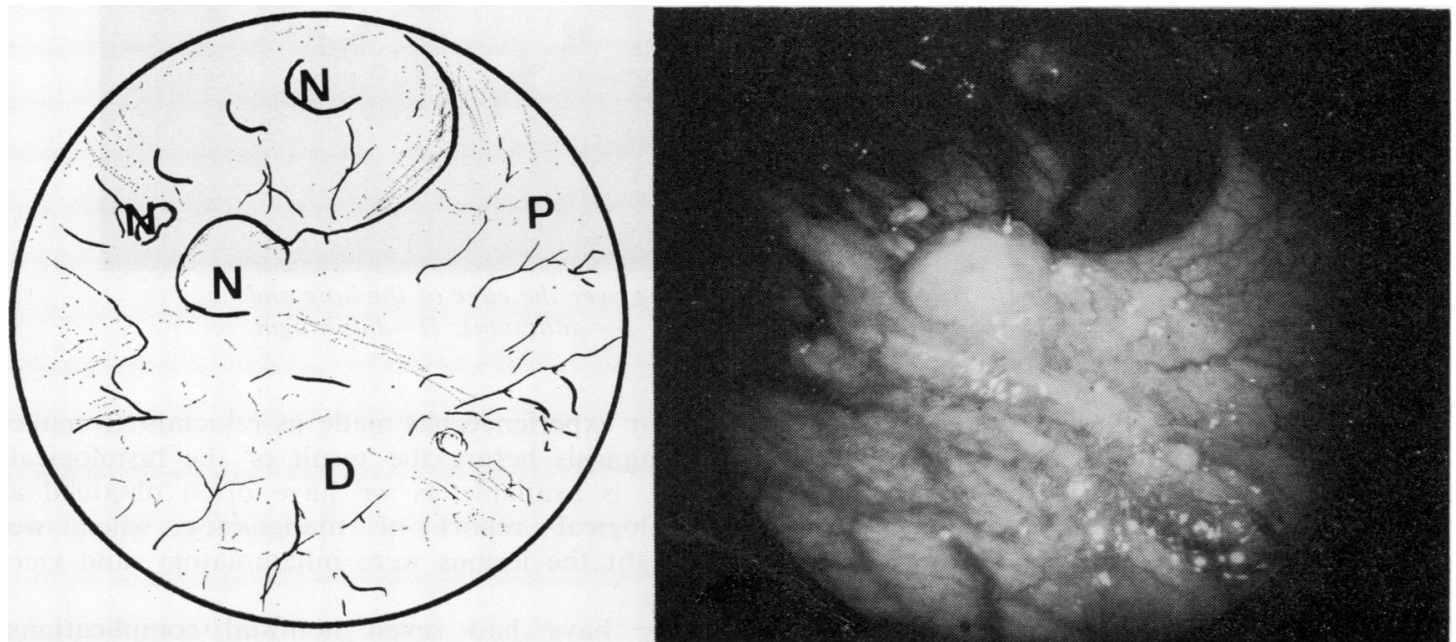

Fig. 2 Thoracoscopic appearance of secondary pleural tumour nodules: $N=$ nodules; $P=$ pericardium; $D=$ diaphragm. 

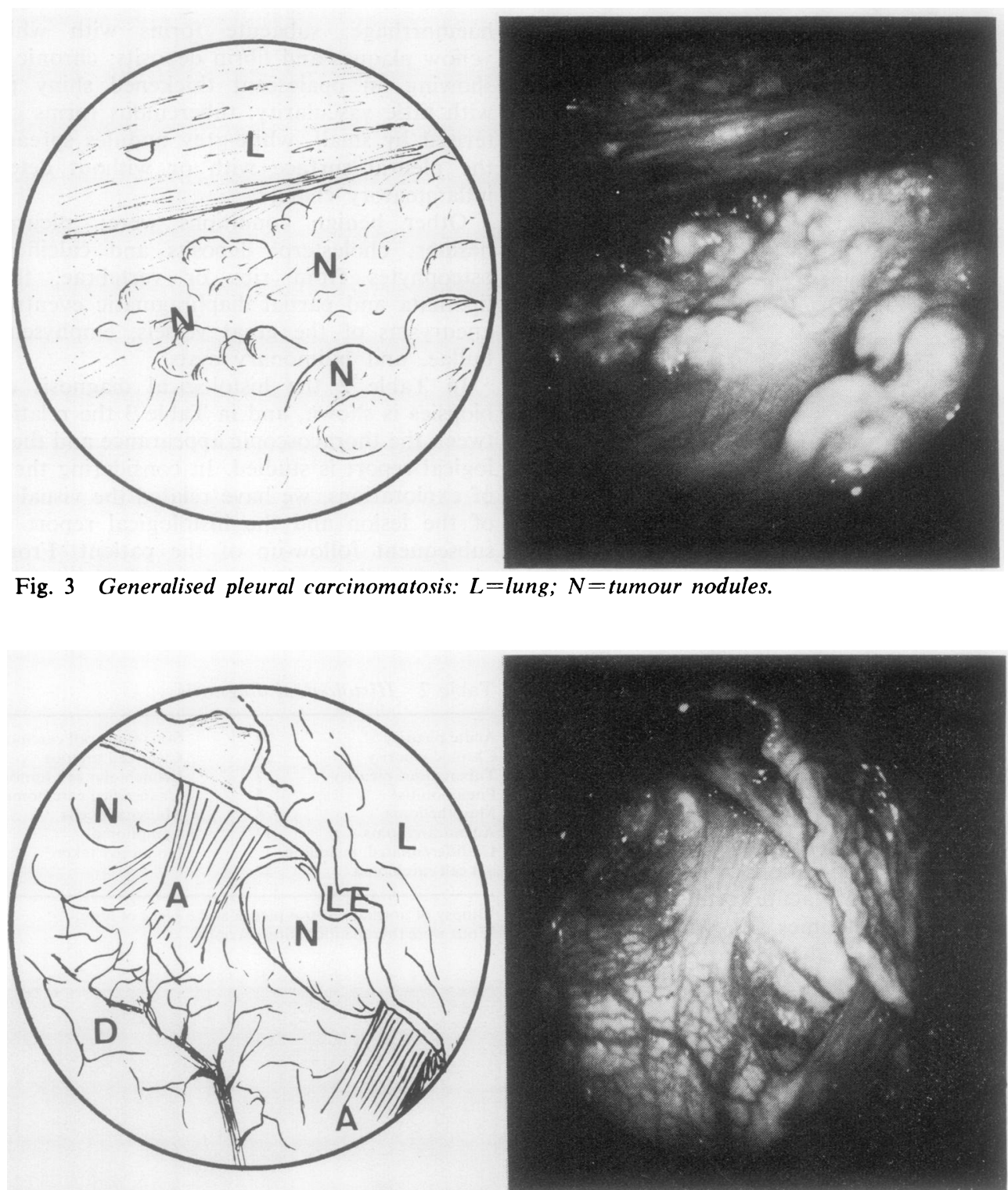

Fig. 4 Tumour of pleura with lymphatic vessels coursing over the edge of the lung and adhesions: $L=$ lung; $L E=$ lymphatic vessels; $N=$ nodules; $A=$ adhesions; $D=$ diaphragm.

demonstrate a tumour, these patients died later of generalised carcinomatosis and the result given by the exploration was considered to be a false negative.

In non-malignant conditions histological study of the biopsy specimen was useful in confirming a benign cause but was usually not helpful in clarifying the real cause of a pleural effusion, except in patients with pleural tuberculosis.
Our experience has made us reluctant to makeo a diagnosis before the result of the histological $\frac{}{\Phi}$ study is available as we have often obtained a? ? histological report of malignancy when we thought the lesions were inflammatory, and vice $\vec{P}$ versa.

We have had seven nonfatal complications $\frac{\mathbb{Q}}{\triangle}$ $(7 / 208=3 \%)$. Three patients with large amountso of fluid and three with persistent air leaks de- 


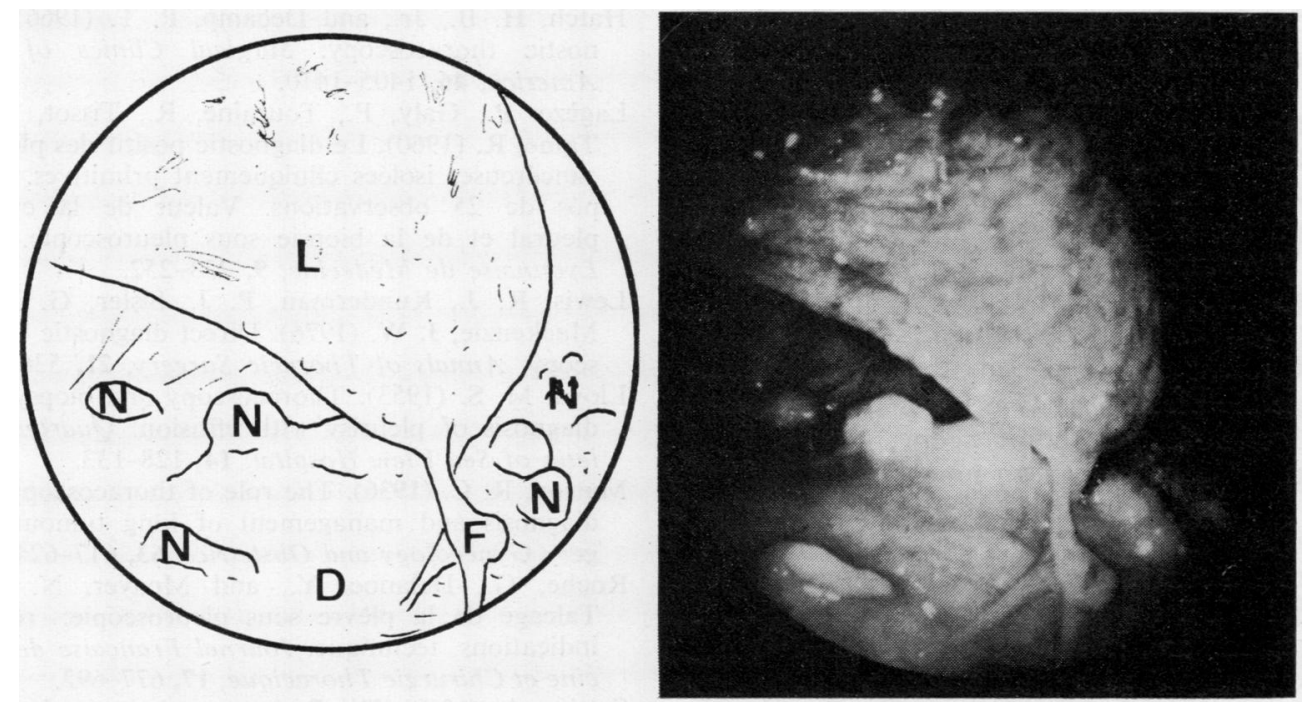

Fig. 5 Tumour and inflammatory changes seen in same field: $F=$ fibrin deposits; $N=$ nodules; $L=$ lung; $D=$ diaphragm.

Table 3 Relation between thoracoscopic appearance and histological report

\begin{tabular}{|c|c|c|c|c|c|c|c|c|}
\hline \multirow{2}{*}{$\begin{array}{l}\text { Suggested diagnosis from } \\
\text { thoracoscopic appearance }\end{array}$} & \multicolumn{8}{|c|}{ Histology } \\
\hline & $\begin{array}{l}\text { Normal } \\
\text { pleura }\end{array}$ & $\begin{array}{l}\text { Acute } \\
\text { pleurisy }\end{array}$ & $\begin{array}{l}\text { Chronic } \\
\text { pleurisy }\end{array}$ & Tuberculosis & Mesothelioma & Carcinomatosis & $\begin{array}{l}\text { Other } \\
\text { tumours }\end{array}$ & No biopsy \\
\hline Normal pleura & 5 & 6 & - & - & - & - & - & - \\
\hline Acute pleurisy & _ & 12 & - & 2 & - & - & - & - \\
\hline Subacute or chronic pleurisy & - & 19 & 9 & - & - & 7 & - & - \\
\hline Tuberculosis & - & - & - & 5 & - & - & - & - \\
\hline Mesothelioma & - & - & 14 & - & 8 & - & - & - \\
\hline Carcinomatosis & - & - & 1 & - & - & 111 & 3 & - \\
\hline Other conditions & - & - & - & - & - & - & - & $6^{1}$ \\
\hline
\end{tabular}

${ }^{1}$ Two foreign bodies, two bullae, one pulmonary aneurysm, one hydatid cyst.

veloped empyemas. In one case the tumour infiltrated the thoracoscopic scar. We had no mortality directly related to the exploration.

\section{Discussion}

We think that thoracoscopy is the best method of making a histological diagnosis in patients with pleural effusions. After considering the clinical findings, the radiological examination, the thoracoscopic appearances, and the pleural biopsy we can obtain a definitive diagnosis more frequently than with other methods.

It is essential to have a free pleural cavity in order to perform thoracoscopy. The existence of a large pleural effusion confirms that the pleural cavity is free from adhesions. When there is a bilateral effusion we first aspirate the smaller effusion and then perform thoracoscopy on the contralateral side.

Our indications are : (1) pleural effusion of uncertain aetiology; (2) effusions associated with lung tumours (in order to establish the existence of pleural metastasis); (3) effusions during or after post-resection radiation therapy or malignant tumours of breast or lung, to detect recurrence of the tumour; and (4) occasionally in order to remove foreign bodies from the pleural cavity or to perform pleurodesis in spontaneous pneumothorax.

Thoracoscopy is contraindicated when thick adhesions are present. Advanced age and respiratory insufficiency are usually not contraindications. In these patients local anaesthesia is used.

We have had few complications. One tumour recurred at the thoracoscopy site. In six patients 
empyemas occurred due to unduly prolonged pleural drainage of a malignant effusion. Biopsy taken from the visceral pleura did not increase the complication rate. We consider that thoracoscopy has the following advantages over blind needle biopsy: (1) the exact place for biopsy can be seen through the thoracoscope (see Figs 2-5) and this gives the maximum chance of diagnosis; (2) biopsies are larger and less traumatised; (3) pleurodesis can be performed; and (4) pleural complications due to pneumothorax are minimal because the pleural cavity is drained.

We conclude that thoracoscopy, when properly performed, can confirm an uncertain diagnosis in most patients with pleural effusion.

We are grateful to the Service of Pneumology and Internal Medicine for referring the patients for investigation and to the Department of Pathology for examining the biopsy specimens.

\section{References}

Abrams, L. D. (1958). A pleural-biopsy punch (Letter). Lancet, 1, 30-31.

Brandt, H. J., and Mai, J. (1971). Diferentialdiagnose des Pleuraergusses durch Thorakoskopie. Pneumologie, 145, 192-203.

Decamp, P. T., Moseley, P. W., Scott, M. L., and Hatch, H. B., Jr. (1973). Diagnostic thoracoscopy. Annals of Thoracic Surgery, 16, 79-84.

Delarue, J., and Depierre, R. (1956). Contribution a l'étude des pleurésies cancéreuses cliniquement primitives. Journal Française de Médecine et Chirurgie Thoracique, 10, 653-663.

Fleishman, S. J., Lichter, A. I., Buchanan, G., and Sichel, R. J. S. (1956). Investigation of idiopathic pleural effusions by thoracoscopy. Thorax, 11, 324327.
Hatch, H. B., Jr., and Decamp, P. T. (1966). Diag- $\overrightarrow{\overrightarrow{\mathrm{C}}}$ nostic thoracoscopy. Surgical Clinics of Northo America, 46, 1405-1410.

Lagèze, P., Galy, P., Touraine, R., Tissot, P., and $\frac{\overline{\bar{m}}}{\overline{5}}$

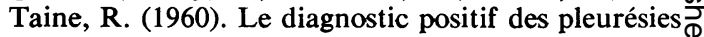
cancéreuses isolées cliniquement primitives. A pro- $Q$ pós de 25 observations. Valeur de la cytologie pleural et de la biopsie sous pleuroscopie. Revue $\vec{O}$ Lyonnaise de Médecine, 9, 233-252.

Lewis, R. J., Kunderman, P. J., Sisler, G. E., and $\vec{\omega}$ Mackenzie, J. W. (1976). Direct diagnostic thoraco-o scopy. Annals of Thoracic Surgery, 21, 536-539.

Lloyd, M. S. (1953). Thoracoscopy and biopsy in the diagnosis of pleurisy with effusion. Quarterly Bulletin of Sea View Hospital, 14, 128-133.

Matson, R. C. (1936). The role of thoracoscopy in the diagnosis and management of lung tumours. Sur-O gery Gynecology and Obstetrics, 63, 617-624.

Roche, G., Delanoe, Y., and Moayer, N. (1963).Talcage de la plèvre scus pleuroscopie: résultats, $O$ indications, technique. Journal Française de Méde-? cine et Chirurgie Thoracique, 17, 677-692.

Sattler, A. (1968). Die Bedeutung der endoskopischen $\stackrel{\mathbb{D}}{-}$ Untersuchung des Pleuraraums für die Diagnostik $\vec{\varphi}$ und Therapie. Médecine et Hygiène, 26, 630.

Senno, A., Moallem, S., Quijano, E. R., Adeyemo, A., and Clauss, R. H. (1974). Thoracoscopy with theo fiberoptic bronchoscope: a simple method in diag-s nosing pleuropulmonary diseases. Journal of Thoracic and Cardiovascular Surgery, 67, 606-611.气

Touraine, R. (1960). La pleuroscopie dans le diag- $\mathbb{D}$ nostic des pleurésies cancéreuses. Journal Française $\overrightarrow{\vec{Z}}$ de Médecine et Chirurgie Thoracique, 14, 735-744.

Requests for reprints to: Dr. F. París, Servicio de Cirurgía Torácica, Centro Hospitalario 'La Fé' 음 Avenida Alferez Provisional 21, Valencia 9, Spain. 